\title{
MicroRNA-214-5p/TGF- $\beta /$ Smad2 signaling alters adipogenic differentiation of bone marrow stem cells in postmenopausal osteoporosis
}

\author{
JIANG QIU $^{1 *}$, GANG HUANG $^{1 *}, \mathrm{NING}^{2} \mathrm{~N}^{2}$ and LIZHONG CHEN ${ }^{1}$ \\ ${ }^{1}$ Division of Organ Transplantation, The First Affiliated Hospital of Sun Yat-sen University, Guangzhou, Guangdong 510080; \\ ${ }^{2}$ Division of Organ Transplantation, The Third Affiliated Hospital of Sun Yat-sen University, \\ Guangzhou, Guangdong 510630, P.R. China
}

Received March 21, 2017; Accepted December 15, 2017

DOI: $10.3892 / \mathrm{mmr} .2018 .8713$

\begin{abstract}
Postmenopausal osteoporosis (OPM) is a common type of osteoporosis in females. It is a systemic, chronic bone disease that presents as microstructure degradation of osseous tissue, decreased bone mineral density and increased osteopsathyrosis caused by hypoovarianism and reduced estrogen levels in the body following menopause. In the present study, the role of microRNA (miR)-214-5p in the regulation of the expression of bone marrow stem cells (BMSCs) was investigated, and its molecular mechanism of osteogenic induction in vitro was assessed. When dexamethasone-induced adipogenic differentiation was performed, miR-214-5p expression was increased compared with the control group, as determined by RT-qPCR. Furthermore, oil red $\mathrm{O}$ staining, RT-qPCR and western blot analysis demonstrated that overexpression of miR-214-5p promoted adipogenic differentiation, inhibited alkaline phosphatase (ALP), runt-related transcription factor 2 (Runx2), osteocalcin (OC) and collagen $\alpha-1$ (I) chain (COL1A1) mRNA expression, and suppressed transforming growth factor (TGF)- $\beta$, phosphorylated (p)-Smad 2 and collagen type IV $\alpha 1$ chain (COL4A1) protein expression in BMSCs. Additionally, downregulation of miR-214-5p increased the ALP, Runx2, OC and COL1 mRNA expression and increased TGF- $\beta, \operatorname{Smad} 2$ and COL4A1 protein expression in BMSCs. Furthermore, a TGF- $\beta$ inhibitor was employed to inhibit TGF- $\beta$ expression in BMSCs following miR-214-5p downregulation, which led to reduced Smad2, TGF- $\beta$ and
\end{abstract}

Correspondence to: $\mathrm{Dr}$ Ning $\mathrm{Na}$, Division of Organ Transplantation, The Third Affiliated Hospital of Sun Yat-sen University, 600 Tian He Road, Guangzhou, Guangdong 510630, P.R. China

E-mail: ningna9740@163.com

${ }^{*}$ Contributed equally

Key words: microRNA-214-5p, adipogenic differentiation, bone marrow stem cells, transforming growth factor $-\beta, \operatorname{Smad} 2$
COL4A1 protein expression, and ALP, Runx2, OC and COL1 mRNA expression was also reduced, compared with the miR-214-5p downregulation only group. It was demonstrated that miR-214-5p may weaken osteogenic differentiation of BMSCs through regulating COL4A1. In conclusion, the results of the present study indicated that miR-214-5p may promote the adipogenic differentiation of BMSCs through regulation of the TGF- $\beta / \mathrm{Smad} 2 / \mathrm{COL} 4 \mathrm{~A} 1$ signaling pathway, and potentially may be used to develop a novel drug for postmenopausal osteoporosis.

\section{Introduction}

Postmenopausal osteoporosis (OPM) is a common type of osteoporosis in females (1). It is a systemic, chronic bone disease that presents as microstructure degradation of osseous tissue, decreased bone mineral density and increased osteopsathyrosis caused by hypoovarianism and reduced estrogen levels in the body following menopause (2). Pathological fracture is a serious complication of the disease and has an incidence rate $>70 \%$ (3). In addition, $>50 \%$ of the female population $>50$ years old suffer from osteoporosis (2). With the rapid increase of the elderly population, the incidence rate of OPM and of fracture is increasing annually (2). Studies have demonstrated that the incidence rate of OPM and fracture is increasing at a growth rate of $18 \%$ every five years worldwide, which seriously influences the health and quality of life of middle-aged and elderly women, and has increased the financial and human burden on society as a whole and family members of patients $(4,5)$.

At present, it is universally recognized that the root cause for OPM incidence is a disequilibrium between bone formation and bone resorption arising from the lack of estrogen, which leads to a disorder of bone reconstruction (6). A previous study primarily focused on abnormally increased bone resorption mediated by osteoclasts (7). Human bone marrow stem cells (BMSCs) are the sourcing cell of osteoblasts in osseous tissue (8). BMSCs serves significant role on bone formation and bone resorption maintaining bone reconstruction process (8). At present, a previous study indicated that the root cause of OPM is the abnormal differentiation of BMSCs, 
which leads to reduced numbers of intraosseous osteoblasts and increased adipocytes (9). However, the specific regulatory mechanism of BMMSC differentiation imbalance remains to be clarified.

MicroRNA (miRNA/miR) are highly conserved short sequence RNAs that exist extensively in animals and plants (10). With the exception of the Y chromosome, the majority of other human chromosomes express miRNA genes (11). The functional mechanism of miRNAs is the specific inhibition or direct regulation of the expression of target genes following degradation and transcription through complementary binding to the $3^{\prime}$ untranslated region of target mRNA (11). According to calculations, $\sim 30-40 \%$ of human genes are regulated by miRNAs at the gene translation level (12). It has been demonstrated that miRNAs serve important regulatory roles on cell proliferation, differentiation, division, apoptosis, signal transduction and other vital processes (11). In addition, miRNAs have been implicated in the initiation and development of various diseases, including cancer, cardiovascular disease, osteoarthritis and bacterial virus infection (11). Furthermore, studies in recent years have demonstrated that miRNAs serve important functions in self-renewal and multidirectional differentiation processes, and may determine the fate of stem cells $(12,13)$.

The TGF- $\beta$ receptor is a serine/threonine kinase receptor and its signal transmission may be conducted through the Smad signaling pathway $(14,15)$. TGF- $\beta$ strengthens the repair capacity following bone injury primarily through promoting enhanced cell division, as well as the generation of osteoblasts and matrix, and type I collagen synthesis (16). The proliferation effect of TGF- $\beta$ significantly increases the number of mesenchymal cells, chondrocytes and osteoblasts, by expression of bone morphogenetic protein (BMP), which may provide an increased number of target cells for osseous tissue regeneration and rehabilitation (14).

Smad protein was discovered in a drosophila and screwworm study originally (17). The protein SMA in caenorhabditis elegans also has the same effect (18). Smad protein serve a significant role in signal transduction following Ser/Thr kinase receptor activation (18). Consequently, the target gene of Smad is the TGF- $\beta$ receptor, which conducts the signal of ligand and receptor function to intermediary molecules of nucleus (18). TGF- $\beta /$ Smads regulates osteogenic differentiation in cells and directly transduces TGF- $\beta$ signals from the cytomembrane to cell nucleus and serves an important role in differentiation $(18,19)$. Members of the TGF- $\beta$ family primarily transfer signals via Smad proteins (17).

Mutations in the collagen type IV $\alpha 1$ chain (COL4A1), a major component of the basilar membrane, have been implicated in various diseases including HANAC syndrome, renal disease, porencephaly, and cataracts $(20,21)$. From 2005, the occurrence of the COL4A1 gene mutation and associated hereditary disease has started to attract the attention $(22,23)$. The COL4A1 gene is the major structural component of the basilar membrane $(22,24)$. COL4A1 is associated with bone mineral density in different parts of the bone $(25,26)$. Li et al (21) demonstrated that the inhibition of miR-214-5p promotes the cell survival of MC3T3-E1 osteoblastic cells by targeting COL4A1. In the present study, the role of the miR-214-5p signaling pathway in adipogenic differentiation of BMSCs was investigated.

\section{Materials and methods}

Identification of HBMSCs and dexamethasone-induced adipogenic differentiation. The PTA-1058 HBMSC cell line was obtained from the American Type Culture Collection (Manassas, VA, USA) and cultured in $\alpha$-minimum essential medium ( $\alpha$-MEM; HyClone; Thermo Fisher Scientific, Inc., Waltham, MA, USA) supplemented with $10 \%$ fetal bovine serum (HyClone; Thermo Fisher Scientific, Inc.), penicillin (100IU/ml;Sigma-Aldrich;MerckKGaA,Darmstadt,Germany) and streptomycin (100 $\mu \mathrm{g} / \mathrm{ml}$, Sigma-Aldrich; Merck KGaA) at $37^{\circ} \mathrm{C}$ in $5 \% \mathrm{CO}_{2}$. HBMSC medium supplemented with dexamethasone (10 mol/l; Sigma-Aldrich; Merck KGaA) was added into HBMSC for 2 weeks. Oil red $\mathrm{O}$ staining was performed to confirm successful adipogenic differentiation following dexamethasone treatment.

miRNA transfection. The miR-214-5p (5'-GGCCTGGCT GGACAGAGTTG-3'), anti-miR-214-5p (5'-ACAGCAGGC ACAGACAGGCAG-3') and negative control (5'-CCCCCC CCCCCCC-3') used in the current study were synthesized by Shanghai GenePharma Co., Ltd. (Shanghai, China). HBMSCs were plated in 6 -well plates ( $50 \%$ confluence) and were transfected with $50 \mathrm{nM}$ miR-214-5p or anti-miR-214-5p using Lipofectamine ${ }^{\circledR} 2000$ (Invitrogen; Thermo Fisher Scientific, Inc.) according to the manufacturer's protocol. In further experiments, $50 \mathrm{nM}$ anti-miR-214-5p was transfected into cells for $4 \mathrm{~h}$ using Lipofectamine ${ }^{\circledR} 2000$, and then fresh $\alpha$-MEM was subsequently added into cells with TGF- $\beta$ inhibitor (10 nM; A 77-01; MedChemExpress China, Shanghai, China) for $48 \mathrm{~h}$ at $37^{\circ} \mathrm{C}$.

Oil red $O$ staining. After transfection, oil red $\mathrm{O}$ staining was conducted in HBMSCs $\left(1 \times 10^{5}\right.$ cell $\left./ \mathrm{ml}\right)$ at 2 weeks following dexamethasone treatment at $37^{\circ} \mathrm{C}$. Cells were washed twice with PBS and fixed with $10 \%$ formalin for $10 \mathrm{~min}$ at $37^{\circ} \mathrm{C}$. Subsequently, cells were stained with filtered oil red $\mathrm{O}$ solution for $1 \mathrm{~h}$ at $37^{\circ} \mathrm{C}$ and observed using a Leica Microsystem fluorescence microscope (DFC300 FX; Leica Microsystems $\mathrm{GmbH}$, Wetzlar, Germany).

Reverse transcription-quantitative polymerase chain reaction $(R T-q P C R)$. Total mRNA was extracted from HMBSCs using TRIzol (Takara Biotechnology Co., Ltd., Dalian, China). A total of 2-4 $\mu \mathrm{g}$ total mRNA was synthesized to cDNA using the PrimeScript 1st Strand cDNA Synthesis kit (Takara Bio, Inc., Otsu, Japan) at $37^{\circ} \mathrm{C}$ for $1 \mathrm{~h}$ and $85^{\circ} \mathrm{C}$ for $1 \mathrm{~min}$. qPCR was performed with $\mathrm{SYBR}^{\circledR}$ Green master mix kit (cat. no. 303402; Takara Bio, Inc., Dalian, China) and an ABI 7300 Real-Time PCR System (Applied Biosystems; Thermo Fisher Scientific, Inc.). The thermal cycling condition was set as $95^{\circ} \mathrm{C}$ for $10 \mathrm{~min}$, followed by 40 cycles of $95^{\circ} \mathrm{C}$ for $30 \mathrm{sec}$ and $60^{\circ} \mathrm{C}$ for $30 \mathrm{sec}$. Primer sequences for $q P C R$ are presented in Table I. The relative expression of miRNA and mRNA to U6 or GAPDH expression, respectively, was measured using the comparative $2^{-\Delta \Delta \mathrm{Cq}}$ method (27).

Western blot analysis. HBMSCs were lysed using radioimmunoprecipitation assay lysis buffer (Beyotime Institute of Biotechnology, Haimen, China) on ice for $30 \mathrm{~min}$ and 


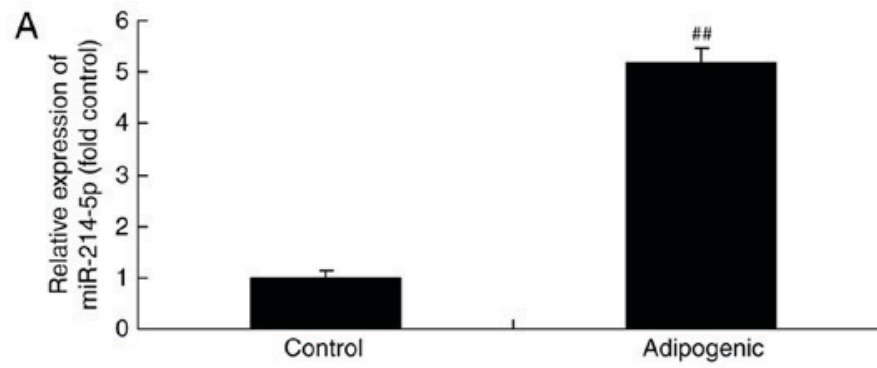

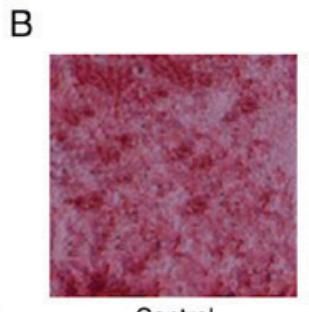

Control

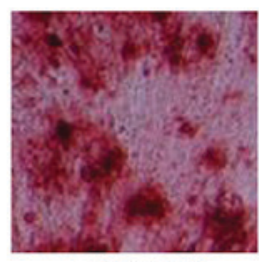

Adipogenic

Figure 1. Expression of miR-214-5p in dexamethasone-induced adipogenic differentiation of human bone marrow stem cells. (A) mRNA expression of miR-214-5p was determined by reverse transcription-quantitative polymerase chain reaction. (B) Successful adipogenic differentiation was determined using oil red $\mathrm{O}$ staining following dexamethasone treatment. Magnification, $\mathrm{x} 100 .{ }^{\# \#} \mathrm{P}<0.01 \mathrm{vs}$. control group. miR, microRNA.

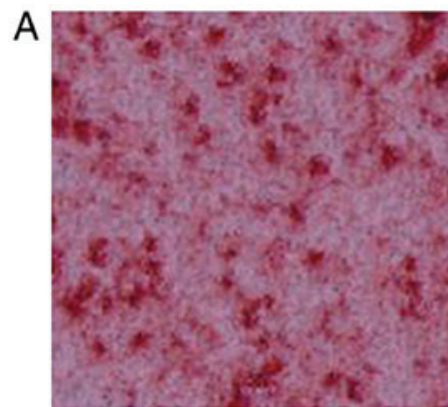

Negative

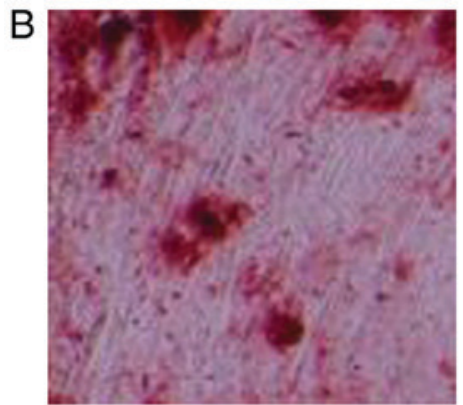

Negative

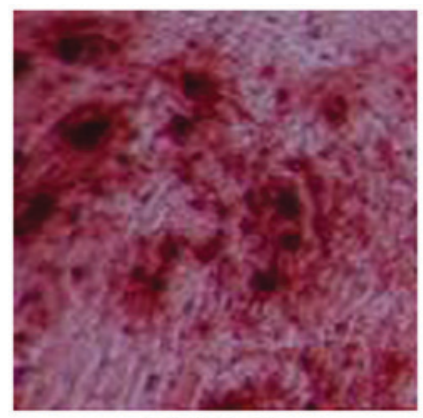

miR-214-5p

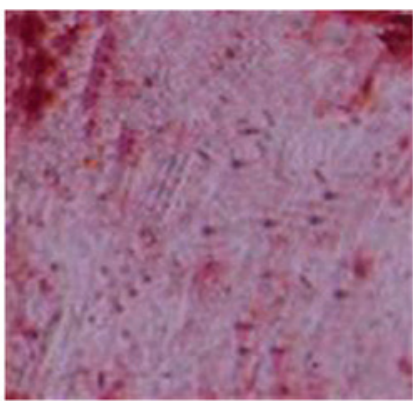

anti-miR-214-5p

Figure 2. Adipogenic differentiation was measured by oil red O staining following miR-214-5p downregulation/overexpression in dexamethasone-treated cells (A) Overexpression of miR-214-5p induced adipogenic differentiation in HBMSCs. (B) miR-214-5p downregulation inhibited adipogenic differentiation in HBMSCs. Magnification, x100. miR, microRNA; HBMSCs, human bone marrow stem cells; negative, negative control transfection group; miR-214-5p group, overexpression of miR-214-5p group; anti-miR-214-5p group, miR-214-5p downregulation group.

supernatants were acquired though centrifugation at $14,000 \mathrm{x} \mathrm{g}$ for $20 \mathrm{~min}$ at $4^{\circ} \mathrm{C}$. Subsequently, proteins were quantified using a bicinchoninic acid assay kit (Beyotime Institute of Biotechnology) and 50-100 $\mu \mathrm{g}$ protein was resolved by $8-10 \%$ SDS-PAGE and transferred to a polyvinylidene difluoride membranes (EMD Millipore, Billerica, MA, USA). Following blocking with $5 \%$ skim milk powder in TBS-0.1\% Tween-20 (TBST) for $1 \mathrm{~h}$ at $37^{\circ} \mathrm{C}$, membranes were incubated overnight at $4^{\circ} \mathrm{C}$ with the following primary antibodies: Anti-TGF- $\beta$ (cat. no. 3709; 1:2,000; Cell Signaling Technology, Inc., Danvers, MA, USA); anti-p-Smad2 (cat. no. 8828; 1:1,000; Cell Signaling Technology, Inc.); anti-COL4A1 (cat. no. sc-517572; 1:1,000; Santa Cruz Biotechnology, Inc., Dallas, TX, USA) and anti-GAPDH (cat. no. 3683; 1:5,000; Cell Signaling Technology, Inc.). Membranes were washed with TBST and incubated with horseradish peroxidase-conjugated anti-rabbit or mouse IgG secondary antibody (cat. nos. 7076 and 7074;
1:5,000; Cell Signaling Technology, Inc.) for $1 \mathrm{~h}$ at room temperature. The membranes were visualized with BeyoECL Plus (Beyotime Institute of Biotechnology, Haimen, China) and analyzed using Image $\mathrm{J}$ x software (National Institutes of Health, Bethesda, MD, USA).

Statistical analysis. Data are presented as the mean \pm standard deviation using SPSS 17.0 (SPSS, Inc., Chicago, IL, USA). Experiments were repeated three times. Data were analyzed using one-way analysis of variance followed by Tukey's post hoc test. $\mathrm{P}<0.05$ was considered to indicate a statistically significant difference.

\section{Results}

Expression of miR-214-5p in dexamethasone-induced adipogenic differentiation of HBMSCs. Initially, miR-214-5p 
Table I. Primer sequences for reverse transcription-quantitative polymerase chain reaction.

\begin{tabular}{lll}
\hline Gene & \multicolumn{1}{c}{ Forward } & \multicolumn{1}{c}{ Reverse } \\
\hline miR-214-5p & 5'-GGCCTGGCTGGACAGA-3' & 5'-GTCACATGACAACCCAGCCT-3' \\
ALP & 5'-TGGAGGTTCAGAAGCTCAACACCA-3' & 5'-ATCTCGTTCTCTGAGTACCAGTC-3' \\
Runx2 & 5'-CCGCACAACCGCACCAT-3' & 5'-CGCTCCGGCCCACAAATCTC-3' \\
OC & 5'-CAGCGGTGCAGAGTCCAGCAAA-3' & 5'-GATGTGGTCAGCCAACTCGTCA-3' \\
COL1A1 & 5'-CCTGGAAAGAATGGAGATGATG-3' & 5'-ATCCAAACCACTGAAACCTCTG-3' \\
PPAR $\gamma$ & 5'-TTATGGAGCCTAAGTTTGAGTTTGC-3' & 5'-TTGTCTTGGATGTCCTCGATGG-3' \\
CEBP $\alpha$ & 5'-GAAGTCGGTGGATAAGAACAGCA-3' & 5'-CTCCAACACCTTCTGCTGCGT-3' \\
Adiponectin & 5'-GTCCCTCCACCCAAGGAAACT-3' & 5'-CTCCTGTCATTCCAGCATCTCC-3' \\
U6 & 5'-CTCGCTTCGGCAGCACATATACT-3' & 5'-ACGCTTCACGAATTTGCGTGTC-3' \\
GAPDH & 5'-GGGCTGCTTTTAACTCTGGT-3' & 5'-GCAGGTTTTTCTAGACGG-3' \\
\hline
\end{tabular}

miR, microRNA; ALP, alkaline phosphatase; Runx2, runt-related transcription factor 2; OC, osteocalcin; COL1A1, collagen type I; PPAR $\gamma$, peroxisome proliferator-activated receptor $\gamma$; CEBP $\alpha$, CCAAT/enhancer-binding protein $\alpha$.

A

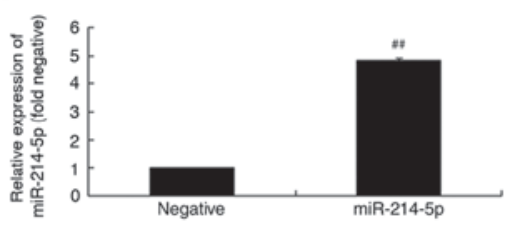

D

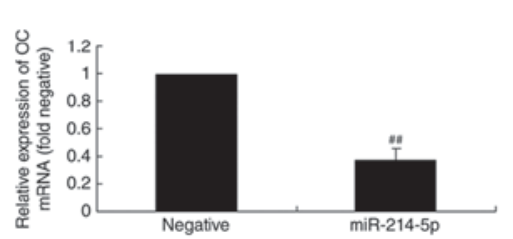

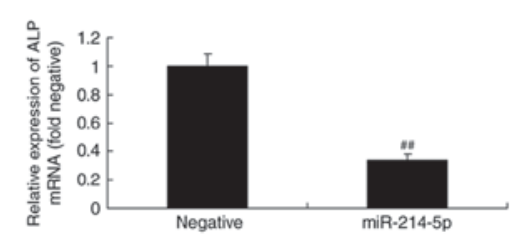

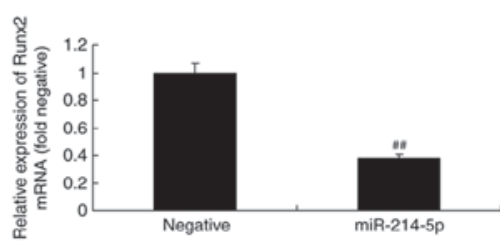

E

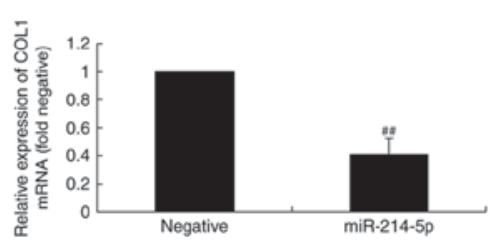

Figure 3. Overexpression of miR-214-5p affected ALP, Runx2, OC and COL1A1 mRNA expression. (A) RT-qPCR was initially performed to confirm successful overexpression of miR-214-5p following transfection. RT-qPCR was subsequently performed to determine the effect of miR-214-5p overexpression on (B) ALP, (C) Runx2, (D) OC and (E) COL1 mRNA expression in human bone marrow stem cells. "\# P<0.01 vs. negative control group. miR, microRNA; ALP, alkaline phosphatase; Runx2, runt-related transcription factor 2; OC, osteocalcin; COL1A1, collagen type IV $\alpha 1$ chain; RT-qPCR, reverse transcription-quantitative polymerase chain reaction; negative, negative control transfection group; miR-214-5p group, overexpression of miR-214-5p group.

expression in dexamethasone-induced adipogenic differentiation of HBMSCs was investigated. It was demonstrated that miR-214-5p expression in dexamethasone-induced differentiated HBMSCs was higher compared with the control group (Fig. 1A), while oil red $\mathrm{O}$ staining demonstrated that dexamethasone treatment led to successful adipogenic differentiation of HBMSCs (Fig. 1B).

miR-214-5p promotes adipogenic differentiation of HBMSCs. Subsequently, the effect of miR-214-5p expression on the adipogenic differentiation of HBMSCs was investigated. Oil red $\mathrm{O}$ staining was performed in miR-214-5p/anti-miR-214-5p-transfected PTA-1058 cells at 2 weeks following dexamethasone treatment. Notably, the results indicated that downregulation of miR-214-5p, through transfection of anti-miR-214-5p, led to reduced oil red O staining and thereby indicated reduced differentiation of PTA-1058 cells, compared with the control group (Fig. 2).
Following overexpression of miR-214-5p, the opposite effect was observed (Fig. 2).

Overexpression of miR-214-5p affects alkaline phosphatase (ALP), runt-related transcription factor 2 (Runx2), OC and COL1A1 mRNA expression in HBMSCs. RT-qPCR was initially performed to confirm successful miR-214-5p overexpression following transfection (Fig. 3A). Subsequently, the mechanism by which miR-214-5p affects adipogenic differentiation of HBMSCs was investigated by measuring the mRNA expression of ALP, Runx2, OC and COL1 in HBMSCs. RT-qPCR indicated that upregulated expression of miR-214-5p led to downregulated expression of ALP, Runx2, OC and COL1 mRNA in HBMSCs cells compared with the negative control group (Fig. 3B-E).

Downregulation of miR-214-5p affects ALP, Runx2, OC and COL1 mRNA expression in HBMSCs. RT-qPCR was initially 
A

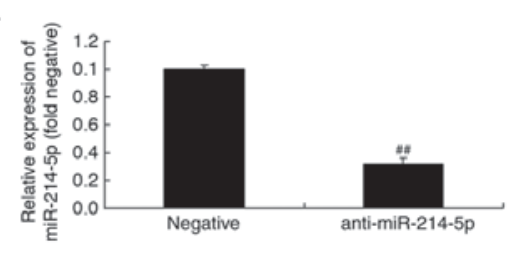

B

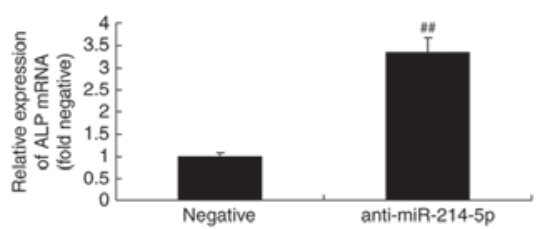

$\mathrm{C}$

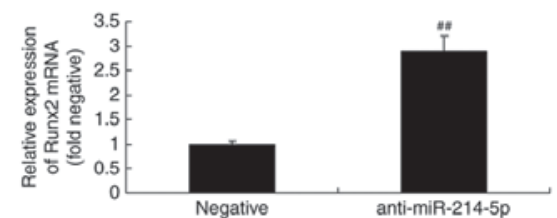

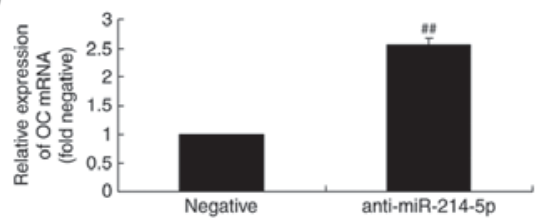

$\mathrm{E}$

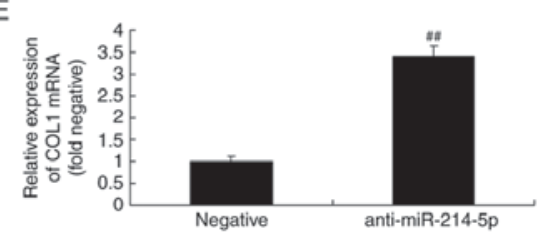

Figure 4. Downregulation of miR-214-5p affected ALP, Runx2, OC and COL1A1 mRNA expression. (A) RT-qPCR was initially performed to confirm successful downregulation of miR-214-5p following transfection. RT-qPCR was subsequently performed to determine the effect of anti-miR-214-5p on (B) ALP, (C) Runx2, (D) OC and (E) COL1 mRNA expression in human bone marrow stem cells. ${ }^{\# \#} \mathrm{P}<0.01$ vs. negative control group. miR, microRNA; ALP, alkaline phosphatase; Runx2, runt-related transcription factor 2; OC, osteocalcin; COL1A1, collagen type IV $\alpha 1$ chain; RT-qPCR, reverse transcription-quantitative polymerase chain reaction; negative, negative control transfection group; anti-miR-214-5p group, miR-214-5p downregulation group.

A

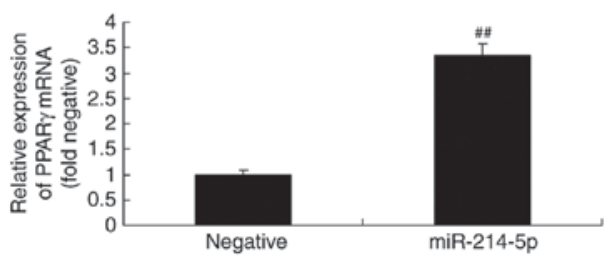

B

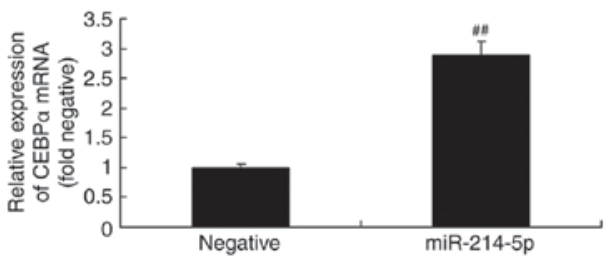

C

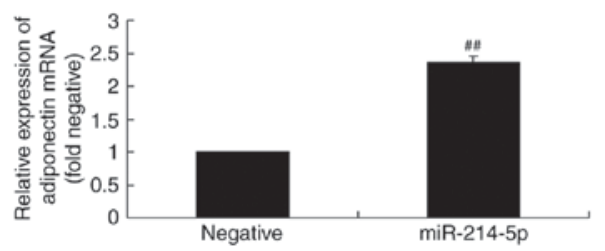

Figure 5. Overexpression of miR-214-5p affected the mRNA expression of PPAR $\gamma, \mathrm{CEBP} \alpha$ and adiponectin. Reverse transcription-quantitative polymerase chain reaction demonstrated that miR-214-5p overexpression increased the mRNA levels of (A) PPAR $\gamma$, (B) CEBP $\alpha$ and (C) adiponectin in human bone marrow stem cells. ${ }^{\# \#} \mathrm{P}<0.01$ vs. negative control group. miR, microRNA; PPAR $\gamma$, peroxisome proliferator-activated receptor $\gamma$; CEBP $\alpha$, CCAAT/enhancer-binding protein $\alpha$; negative, negative control transfection group; miR-214-5p group, overexpression of miR-214-5p group.

performed to confirm successful miR-214-5p downregulation following transfection of anti-miR-214-5p (Fig. 4A). Furthermore, as demonstrated in Fig. 4B-E, downregulation of miR-214-5p led to increased ALP, Runx2, OC and COL1 mRNA expression in HBMSCs compared with the negative control group. ator-activated receptor $\gamma(P P A R \gamma), C C A A T /$ enhancer-binding
A

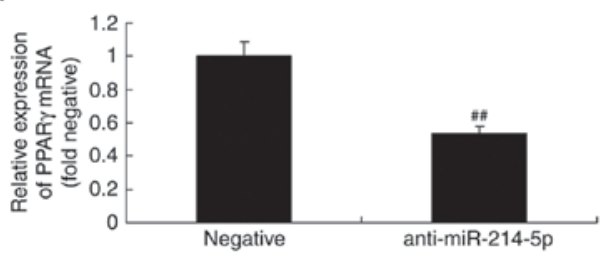

B

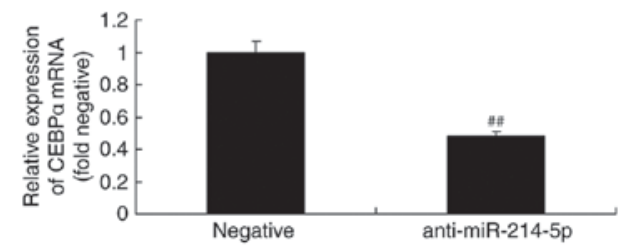

C

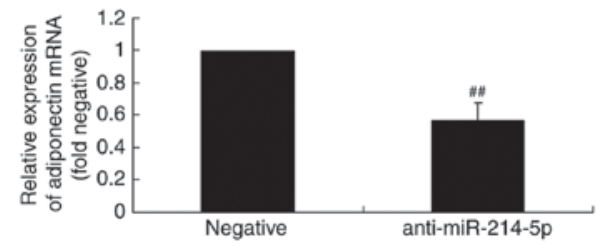

Figure 6. Downregulation of miR-214-5p affected the mRNA expression of PPAR $\gamma, \mathrm{CEBP} \alpha$ and adiponectin. Reverse transcription-quantitative polymerase chain reaction demonstrated that miR-214-5p downregulation reduced the levels of (A) PPAR $\gamma$, (B) CEBP $\alpha$ and (C) adiponectin in human bone marrow stem cells. ${ }^{\# \#} \mathrm{P}<0.01$ vs. negative control group. miR, microRNA; PPAR $\gamma$, peroxisome proliferator-activated receptor $\gamma$; CEBP $\alpha, \mathrm{CCAAT/enhancer-binding} \mathrm{protein} \alpha$; negative, negative control transfection group; anti-miR-214-5p group, miR-214-5p downregulation group.

protein $\alpha(C E B P \alpha)$ and adiponectin $m R N A$ expression in HBMSCs. PPAR $\gamma, \mathrm{CEBP} \alpha$ and adiponectin regulates osteogenic differentiation of HBMSCs (28), therefore the expression of PPAR $\gamma, \mathrm{CEBP} \alpha$ and adiponectin of HBMSCs by miR-214-5p was investigated. The mRNA levels of PPAR $\gamma, \mathrm{CEBP} \alpha$ and adiponectin in HBMSCs were also investigated following overexpression of miR-214-5p. As illustrated in Fig. 5, the mRNA expression levels of PPAR $\gamma, \mathrm{CEBP} \alpha$ and adiponectin 
A

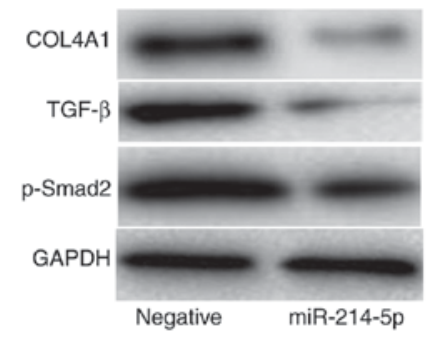

C

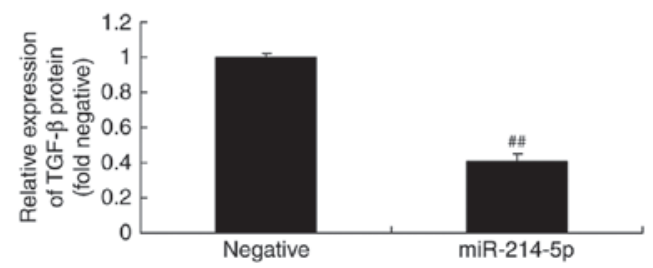

B

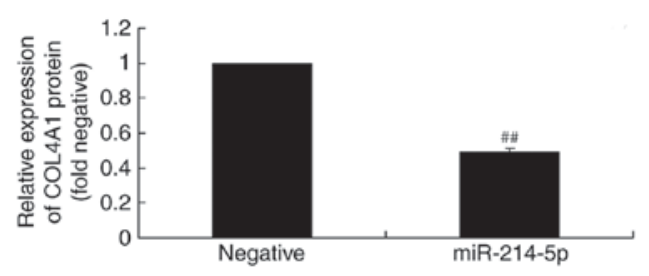

D

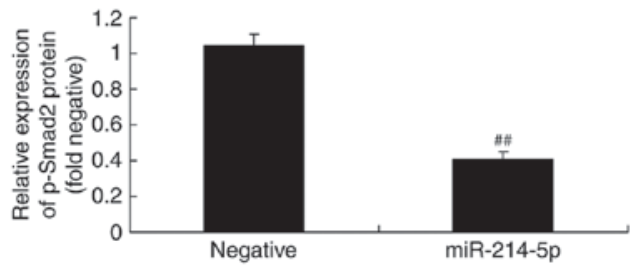

Figure 7. Overexpression of miR-214-5p suppressed COL4A1, TGF- $\beta$ and $p-S m a d 2$ protein levels. (A) Western blot analysis demonstrated that miR-214-5p overexpression reduced the protein levels of COL4A1, TGF- $\beta$ and p-Smad2. Densitometric analysis of western blotting results was performed to quantify the protein expression of (B) COL4A1, (C) TGF- $\beta$ and (D) p-Smad2 following overexpression of miR-214-5p in human bone marrow stem cells. ${ }^{\# \#} \mathrm{P}<0.01 \mathrm{vs.}$ negative control group. miR, microRNA; COL4A1, collagen type IV $\alpha 1$ chain; TGF- $\beta$, transforming growth factor- $\beta$; p-Smad2, phosphorylated-Smad2; negative, negative control transfection group; miR-214-5p group, overexpression of miR-214-5p group.

A

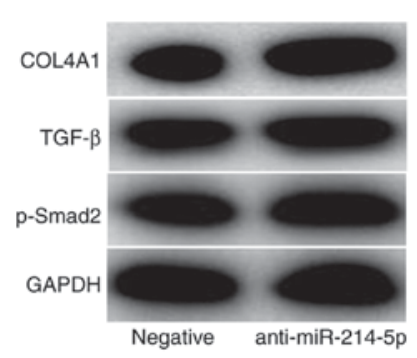

C

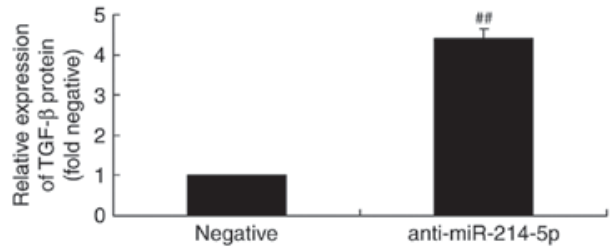

B

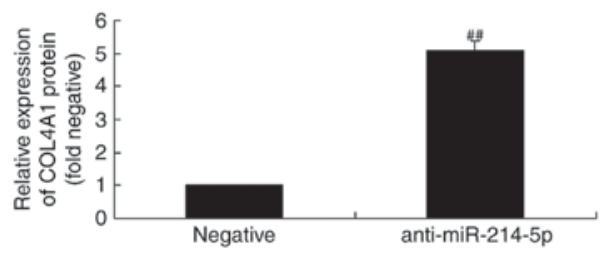

$\mathrm{D}$

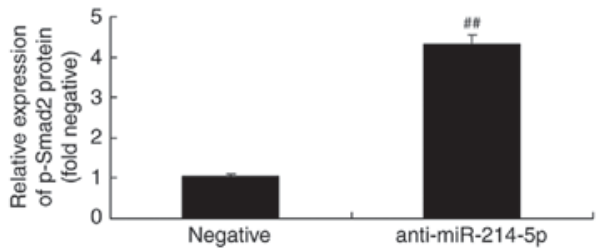

Figure 8. Downregulation of miR-214-5p enhanced the protein expression of COL4A1, TGF- $\beta$ and p-Smad2. (A) Western blot analysis demonstrated that miR-214-5p downregulation increased the protein levels of COL4A1, TGF- $\beta$ and p-Smad2. Densitometric analysis of western blotting results was performed to quantify the protein expression of (B) COL4A1, (C) TGF- $\beta$ and (D) p-Smad2 following downregulation of miR-214-5p in human bone marrow stem cells. ${ }^{\# \#} \mathrm{P}<0.01$ vs. negative control group. miR, microRNA; COL4A1, collagen type IV $\alpha 1$ chain; TGF- $\beta$, transforming growth factor- $\beta$; p-Smad2, phosphorylated-Smad2; negative, negative control transfection group; anti-miR-214-5p group, miR-214-5p downregulation group.

following miR-214-5p overexpression were higher compared with the negative control group.

Downregulation of miR-214-5p affects PPAR , CEBP $\alpha$ and adiponectin $m R N A$ expression in HBMSCs. By contrast, following downregulation of miR-214-5p, the mRNA levels of PPAR $\gamma$, CEBP $\alpha$ and adiponectin were lower compared with the negative control group (Fig. 6).

Overexpression of miR-214-5p suppresses COL4A1, $T G F-\beta$ and $p$-Smad 2 protein expression in HBMSCs. The association between miR-214-5p expression and COL4A1, TGF- $\beta$ and $\mathrm{p}-\mathrm{Smad} 2$ protein expression in
HBMSCs was investigated by western blot analysis. The results demonstrated that overexpression of miR-214-5p suppressed COL4A1, TGF- $\beta$ and $\mathrm{p}$-Smad 2 protein expression in HBMSCs, compared with the negative control group (Fig. 7).

Downregulation of miR-214-5p activates COL4A1, TGF- $\beta$ and $p$-Smad 2 protein expression in HBMSCs. By contrast, western blot analysis results following downregulation of miR-214-5p in HBMSCs demonstrated that the protein expression of COL4A1, TGF- $\beta$ and $p-S m a d 2$ was increased, compared with the negative control group (Fig. 8). 
A

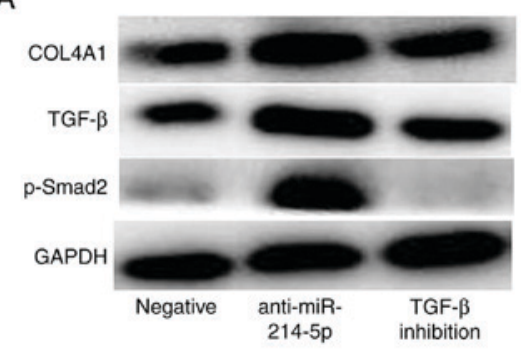

C

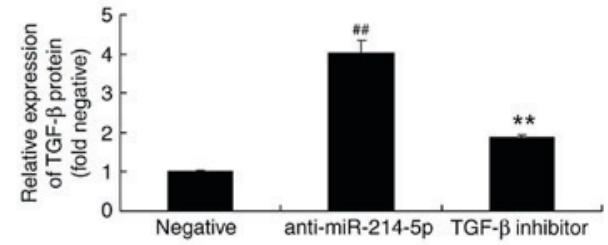

B

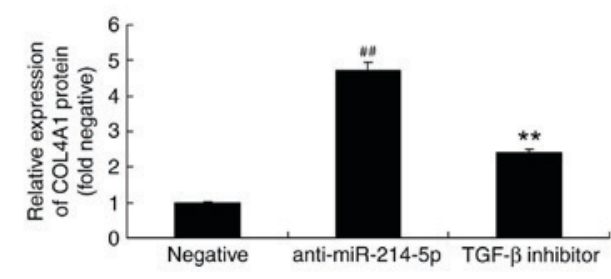

D

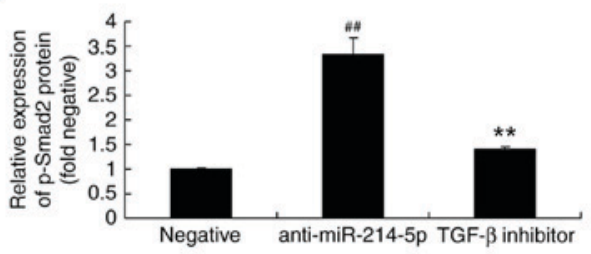

E

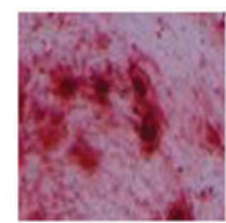

Negative

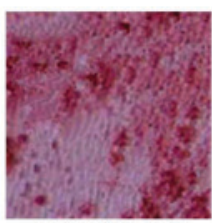

anti-miR-214-5p

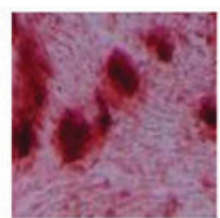

TGF- $\beta$ inhibitor

Figure 9. TGF- $\beta$ inhibitor reversed the effects of miR-214-5p downregulation on the protein expression of COL4A1, TGF- $\beta$ and p-Smad2. (A) Western blot analysis demonstrated that TGF- $\beta$ inhibitor reversed anti-miR-214-5p-induced increases in the protein expression of COL4A1, TGF- $\beta$ and p-Smad2. Densitometric analysis of western blotting results was performed to quantify the protein expression of (B) COL4A1, (C) TGF- $\beta$ and (D) p-Smad2 following downregulation of miR-214-5p with or without TGF- $\beta$ inhibitor treatment in human bone marrow stem cells. (E) Following miR-214-5p downregulation with or without TGF- $\beta$ inhibitor treatment, adipogenic differentiation was assessed using oil red $\mathrm{O}$ staining. Magnification, $\mathrm{x} 100$. ${ }^{\# \#} \mathrm{P}<0.01 \mathrm{vs}$. negative control group; "* $\mathrm{P}<0.01$ vs. anti-miR-214-5p group. TGF- $\beta$, transforming growth factor- $\beta$; miR, microRNA; COL4A1, collagen type IV $\alpha 1$ chain; $p$-Smad2, phosphorylated-Smad2; negative, negative control transfection group; anti-miR-214-5p group, miR-214-5p downregulation group; TGF- $\beta$ inhibitor group, miR-214-5p downregulation+TGF- $\beta$ inhibitor group.

A

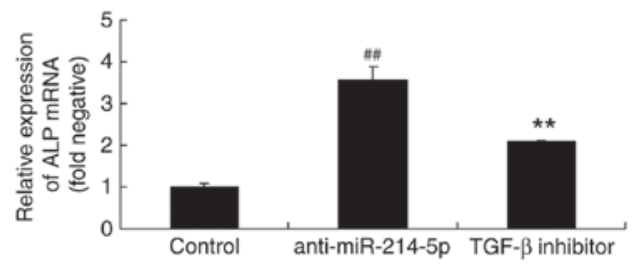

C

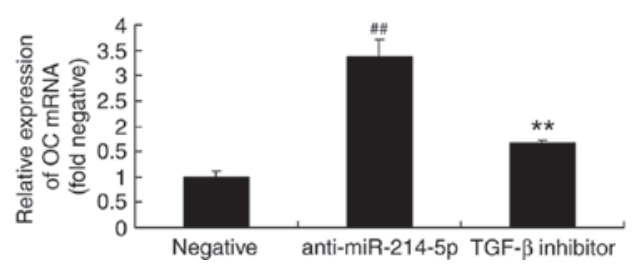

B

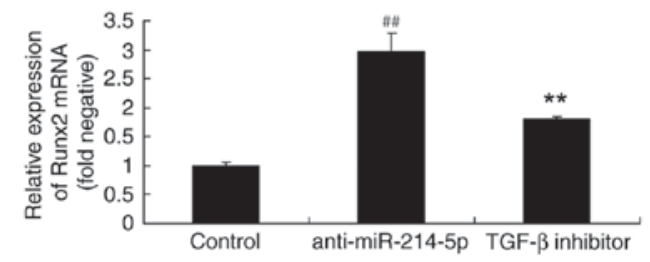

D

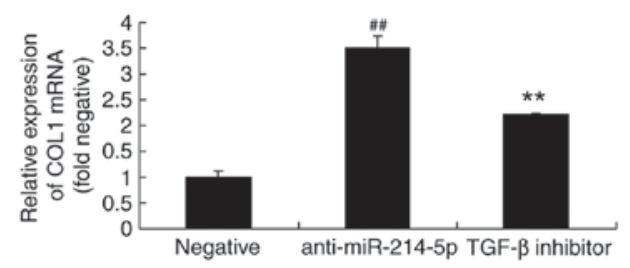

Figure 10. TGF- $\beta$ inhibitor reversed the effects of miR-214-5p downregulation on the mRNA expression of ALP, Runx2, OC and COL1. Reverse transcription-quantitative polymerase chain reaction demonstrated that TGF- $\beta$ inhibitor reversed the anti-miR-214-5p-induced increases in the mRNA expression of (A) ALP, (B) Runx2, (C) OC and (D) COL1 in human bone marrow stem cells. ${ }^{\# \#} \mathrm{P}<0.01$ vs. negative control group; ${ }^{* *} \mathrm{P}<0.01$ vs. anti-miR-214-5p group. TGF- $\beta$, transforming growth factor- $\beta$; miR, microRNA; ALP, alkaline phosphatase; Runx2, runt-related transcription factor 2; OC, osteocalcin; COL1A1, collagen type IV $\alpha 1$ chain; negative, negative control transfection group; anti-miR-214-5p group, miR-214-5p downregulation group; TGF- $\beta$ inhibitor group, miR-214-5p downregulation+TGF- $\beta$ inhibitor group. 
A

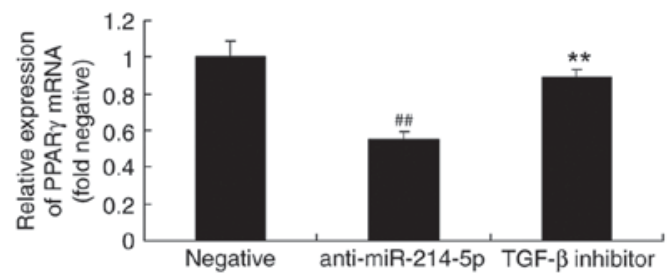

B

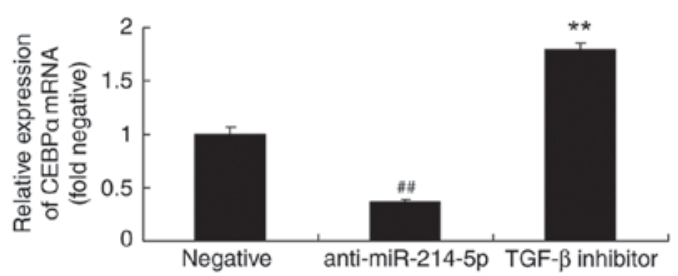

C

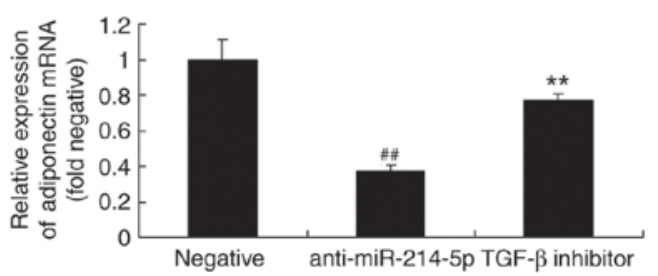

Figure 11. TGF- $\beta$ inhibitor reversed the effects of miR-214-5p downregulation on the mRNA expression of PPAR $\gamma, \mathrm{CEBP} \alpha$ and adiponectin. Reverse transcription-quantitative polymerase chain reaction demonstrated that TGF- $\beta$ inhibitor reversed the anti-miR-214-5p-induced reduction in the mRNA expression of (A) PPAR $\gamma$, (B) CEBP $\alpha$ and (C) adiponectin in human bone marrow stem cells. ${ }^{\#} \mathrm{P}<0.01$ vs. negative control group; ${ }^{* * *} \mathrm{P}<0.01$ vs. anti-miR-214-5p group. TGF- $\beta$, transforming growth factor- $\beta$; miR microRNA; PPAR $\gamma$, peroxisome proliferator-activated receptor $\gamma$; CEBP $\alpha$, CCAAT/enhancer-binding protein $\alpha$; negative, negative control transfection group; anti-miR-214-5p group, miR-214-5p downregulation group; TGF- $\beta$ inhibitor group, miR-214-5p downregulation + TGF- $\beta$ inhibitor group.

investigated by measuring the protein expression of COL4A1, TGF- $\beta$ and $p$-Smad2 following miR-214-5p downregulation with or without the addition of a TGF- $\beta$ inhibitor. The results demonstrated that the addition of the TGF- $\beta$ inhibitor $(10 \mathrm{nM}$ for $48 \mathrm{~h})$ reduced the effect that the downregulation of miR-214-5p had on COL4A1, TGF- $\beta$ and $p-S m a d 2$ protein expression, and oil red O staining in HBMSCs (Fig. 9A-E).

TGF- $\beta$ inhibitor affects ALP, Runx2, OC and COL1 mRNA expression in HBMSCs following miR-214-5p downregulation. The impact of aTGF- $\beta$ inhibitor on the anti-miR-214-5p-mediated effects on ALP, Runx2, OC and COL1 mRNA expression were also investigated by RT-qPCR. The results demonstrated that the TGF- $\beta$ inhibitor affected ALP, Runx2, OC and COL1 mRNA expression in HBMSCs following miR-214-5p downregulation by reversing the anti-miR-214-5p-induced increase in the expression of these genes (Fig. 10).

TGF- $\beta$ inhibitor affects PPAR $\gamma, C E B P \alpha$ and adiponectin $m R N A$ expression in HBMSCs following miR-214-5p downregulation. Similarly, following miR-214-5p downregulation in the presence of the TGF- $\beta$ inhibitor, the mRNA expression of PPAR $\gamma$, CEBP $\alpha$ and adiponectin in HBMSCs was increased compared with the anti-miR-214-5p group without TGF- $\beta$ inhibitor (Fig. 11).

\section{Discussion}

BMSCs are a type of stem cell deriving from mesoblasts with self-renewal and multidirectional differentiation potential (6). BMSC sampling is convenient as it is easy to perform separation and cultivation (29). BMSCs are characterized by vulnerability to exogenous gene transfection, stable expression, rapid in vitro proliferation and low immunogenicity (4). Under specific in vitro induction conditions, BMSCs are able to differentiate into osteoblasts, reticular cells, chondroblasts, adipocytes, neuroblasts, stromal cells and various other cell lineages. BMSCs are the most commonly used cell line for tissue engineering in recent years (2). Due to the multipotent differentiation properties of BMSCs, multiple target point injection can be performed through the arteriovenous route conveying the BMSCs through blood circulation to the lesion, which improved disease symptoms or signs, and promoted wound healing (30). The present study demonstrated that miR-214-5p expression in dexamethasone-induced adipogenic differentiation of HBMSC group was increased compared with control cells. Furthermore, overexpression of miR-214-5p increased adipogenic differentiation, and suppressed ALP, Runx2, OC and AP mRNA expression in HBMSCs. Downregulation of miR-214-5p in HBMSCs led to opposing effects, which indicated that miR-214-5p expression may be an important factor in adipogenic differentiation. In the present study, only oil red O staining was used to analyze the phenotype of BMSCs, which is a limitation as additional methods assessing the phenotype of BMSCs are required in future studies.

TGF- $\beta$ is a type of polypeptide growth factor that is abundantly expressed and is enriched in the osseous tissue (15). It regulates the proliferation and differentiation of various cell types, including osteoblasts and osteoclasts, and affects the bone matrix synthesis (15). At a concentration $>5 \mathrm{ng} / \mathrm{ml}$, TGF- $\beta$ was demonstrated to enhance the proliferation speed of BMSCs (15). Furthermore, TGF- $\beta$ has been reported to affect chondrocytes and inhibit the generation of collagen type II, while in osteoblasts it induced COL1 production, thus reducing the cartilage damage period during bone repair (15). TGF- $\beta$ has also been reported to promote matrix differentiation (31). In the present study, overexpression of miR-214-5p suppressed TGF- $\beta$ protein expression in HBMSCs. However, only western blot analysis was used to analyze alterations in the TGF- $\beta$ protein expression following miR-214-5p overexpression/downregulation, which is a further limitation of the present study. Therefore, additional methods are required in order to investigate the potential mechanisms of miR-214-5p on adipogenic differentiation in OPM.

TGF- $\beta$ and various cytokines have been previously reported to regulate the activity of Runx2 (32), which is an essential protein for the skeleton growth process. In vitro experiments demonstrated that TGF- $\beta$ promoted the proliferation and differentiation of ectomesenchymal cells periosteum, promoted the proliferation of osteogenesis (cartilage) cells and stimulated osteogenesis-associated genes, including increases in Runx 2 mRNA expression and the synthesis of osteonectin, osteopontin and COL1 (31). Furthermore, it was demonstrated to inhibit the generation of osteoclasts and the activity of mature osteoclasts, 
thus inhibiting bone resorption and reducing concomitant markers (27). In the present study, the results demonstrated that downregulation of miR-214-5p induced TGF- $\beta$ protein expression in HBMSCs. Iizuka et al (33) reported that miR-214-5p may have crucial roles in the progression of liver fibrosis through TGF- $\beta$ stimulation. So, miR-214-5p was considered to regulate TGF- $\beta$ protein expression to affect HBMSCs.

Smad proteins directly participate in signaling transduction processes of the TGF- $\beta$ superfamily (19). They function as the downstream signal of TGF- $\beta$ and transfer it to the nucleus (34). Following the detection of the Smad genes, considerable progress and development was made concerning the signal transduction of the TGF- $\beta$ superfamily. The gene regulatory mechanism by Smads is complex $(18,34)$. A single gene may be regulated by various regulatory mechanisms that determine its expression level. Smad proteins transfer TGF- $\beta$ signals to the nucleus and precisely control the expression of certain genes to alter cell phenotype and functions. The present study demonstrated that overexpression of miR-214-5p suppressed p-Smad2 protein expression in HBMSCs, which showed that miR-214-5p inhibits the TGF- $\beta /$ Smad signaling pathway to induce adipogenic differentiation in HBMSCs.

Previous studies illustrated that COL4A1 gene mutations were associated with cerebral hemorrhage, microaneurysm, ocular phenotype and kidney diseases of newborns and adults $(22,35)$. A number of studies have investigated the COL4A1 gene as a potential candidate gene of osteoporosis $(22,35)$. The COL4A1 gene can transform from an acyl amino acid to histidine (35). The COL4A1 presented significant correlation with the thigh bone and collar bone density $(21,36)$. In the present study, overexpression of miR-214-5p suppressed COL4A1 protein expression in HBMSCs. PPAR $\gamma, \mathrm{CEBP} \alpha$ and adiponectin regulates osteogenic differentiation of HBMSCs (28), therefore the expression of PPAR $\gamma, \mathrm{CEBP} \alpha$ and adiponectin of HBMSCs by miR-214-5p was investigated. Then, it was demonstrated that the mRNA expression levels of PPAR $\gamma, \operatorname{CEBP} \alpha$ and adiponectin following miR-214-5p overexpression were higher compared with the negative control group. So, these results demonstrated that miR-214-5p overexpression induced PPAR $\gamma, \mathrm{CEBP} \alpha$ and adiponectin of HBMSCs.

In conclusion, the present study demonstrated that miR-214-5p promoted adipogenic differentiation of BMSCs by TGF- $\beta /$ Smad2/COL4A1 signaling pathway. Furthermore, it was confirmed that miR-214-5p may also be involved in the regulation of HBMSC adipogenic differentiation, and treatment for OPM in further clinical.

\section{Acknowledgements}

Not applicable.

\section{Funding}

The present study was supported by the Nature Scientific Foundation of Guangdong Province, China (grant no.2016A030313190), the National Nature Scientific Foundation of China (grant nos. 81470977 and 81270835), the Science and
Technology Planning Project of Guangdong Province, China (grant nos. 2013B021800077 and 2014A020212121) and the Basic Service Charge Young Teachers Cultivation Project of Sun Yat-sen University (grant no. 13ykpy35).

\section{Availability of data and materials}

The analyzed data sets generated during the study are available from the corresponding author on reasonable request.

\section{Authors' contributions}

NN designed the experiment and wrote the manuscript. JQ, $\mathrm{GH}$ and LC performed the experiment. JQ and NN analyzed the data.

\section{Ethics approval and consent to participate}

Not applicable.

\section{Consent for publication}

Not applicable.

\section{Competing interests}

The authors declare that they have no competing interests.

\section{References}

1. Pawlowski JW, Martin BR, McCabe GP, McCabe L, Jackson GS, Peacock M, Barnes $\mathrm{S}$ and Weaver CM: Impact of equol-producing capacity and soy-isoflavone profiles of supplements on bone calcium retention in postmenopausal women: A randomized crossover trial. Am J Clin Nutr 102: 695-703, 2015

2. Pfeifer M, Kohlwey L, Begerow B and Minne HW: Effects of two newly developed spinal orthoses on trunk muscle strength, posture, and quality-of-life in women with postmenopausal osteoporosis: A randomized trial. Am J Phys Med Rehabil 90: 805-815, 2011.

3. Kessous R, Weintraub AY, Mattan Y, Dresner-Pollak R, Brezis M Liebergall $\mathrm{M}$ and Kandel L: Improving compliance to osteoporosis workup and treatment in postmenopausal patients after a distal radius fracture. Taiwan J Obstet Gynecol 53: 206-209, 2014.

4. Itabashi A, Yoh K, Chines AA, Miki T, Takada M, Sato H, Gorai I, Sugimoto T, Mizunuma H, Ochi H, et al: Bridging analysis of the efficacy and safety of bazedoxifene in Japanese and global populations of postmenopausal women with osteoporosis. J Bone Miner Metab 33: 61-72, 2015

5. Filip R, Possemiers S, Heyerick A, Pinheiro I, Raszewski G Davicco MJ and Coxam V: Twelve-month consumption of a polyphenol extract from olive (Olea europaea) in a double blind, randomized trial increases serum total osteocalcin levels and improves serum lipid profiles in postmenopausal women with osteopenia. J Nutr Health Aging 19: 77-86, 2015.

6. Gu JM, Wang L, Lin H, Chen DC, Tang H, Jin XL, Xia WB $\mathrm{Hu}$ YQ, Fu WZ, He JW, et al: The efficacy and safety of weekly 35-mg risedronate dosing regimen for Chinese postmenopausal women with osteoporosis or osteopenia: 1-year data. Acta Pharmacol Sin 36: 841-846, 2015.

7. Huang C, Zhang GF, Han J, Liao GJ and Zou BG: Mechanism of age-related changes of bone marrow mesenchymal stem cells in senile osteoporosis. J Biol Regul Homeost Agents 30: 565-569, 2016.

8. Li F, Zhou C, Xu L, Tao S, Zhao J and Gu Q: Effect of stem cell therapy on bone mineral density: A meta-analysis of preclinical studies in animal models of osteoporosis. PLoS One 11: e0149400, 2016. 
9. Zavrski I, Naujokat C, Niemöller K, Jakob C, Heider U, Langelotz C, Fleissner C, Eucker J, Possinger K and Sezer O: Proteasome inhibitors induce growth inhibition and apoptosis in myeloma cell lines and in human bone marrow myeloma cells irrespective of chromosome 13 deletion. J Cancer Res Clin Oncol 129: 383-391, 2003.

10. Heilmeier U, Hackl M, Skalicky S, Weilner S, Schroeder F, Vierlinger K, Patsch JM, Baum T, Oberbauer E, Lobach I, et al: Serum microRNAs are indicative of skeletal fractures in postmenopausal women with and without type 2 diabetes and influence osteogenic and adipogenic differentiation of adipose-tissue derived mesenchymal stem cells in vitro. J Bone Miner Res 31: 2173-2192, 2016.

11. Liu Y, Wang Y, Yang N, Wu S, Lv Y and Xu L: In silico analysis of the molecular mechanism of postmenopausal osteoporosis. Mol Med Rep 12: 6584-6590, 2015.

12. Cao Z, Moore BT, Wang Y, Peng XH, Lappe JM, Recker RR and Xiao P: MiR-422a as a potential cellular microRNA biomarker for postmenopausal osteoporosis. PLoS One 9: e97098, 2014.

13. Liu XD, Cai F, Liu L, Zhang Y and Yang AL: MicroRNA-210 is involved in the regulation of postmenopausal osteoporosis through promotion of VEGF expression and osteoblast differentiation. Biol Chem 396: 339-347, 2015.

14. Cheng Q, Tang W, Sheu TJ, Du Y, Gan J, Li H, Hong W, Zhu X, Xue $S$ and Zhang X: Circulating TGF- $\beta 1$ levels are negatively correlated with sclerostin levels in early postmenopausal women. Clin Chim Acta 455: 87-92, 2016.

15. Sun J, Zhang $\mathrm{C}, \mathrm{Xu} \mathrm{L}$, Yang $\mathrm{M}$ and Yang $\mathrm{H}$ : The transforming growth factor- $\beta 1$ (TGF- $\beta 1$ ) gene polymorphisms (TGF- $\beta 1$ T869C and TGF- $\beta 1$ T29C) and susceptibility to postmenopausal osteoporosis: a meta-analysis. Medicine 94: e461, 2015.

16. Utennam D, Tungtrongchitr A, Phonrat B, Tungtrongchitr R and Preutthipan S: Association of T869C gene polymorphism of transforming growth factor- $\beta 1$ with low protein levels and anthropometric indices in osteopenia/osteoporosis postmenopausal Thai women. Genet Mol Res 11: 87-99, 2012.

17. Sun X, Cao Z, Zhang Q, Li M, Han L and Li Y: Aluminum trichloride inhibits osteoblast mineralization via TGF- $\beta 1 / \mathrm{Smad}$ signaling pathway. Chem Biol Interact 244: 9-15, 2016.

18. Li B: Bone morphogenetic protein-Smad pathway as drug targets for osteoporosis and cancer therapy. Endocr Metab Immune Disord Drug Targets 8: 208-219, 2008.

19. Donoso O, Pino AM, Seitz G, Osses N and Rodriguez JP: Osteoporosis-associated alteration in the signalling status of BMP-2 in human MSCs under adipogenic conditions. J Cell Biochem 116: 1267-1277, 2015.

20. Matsumoto T, Miyakoshi K, Fukutake M, Ochiai D, Minegishi K and Tanaka M: Intracranial sonographic features demonstrating in utero development of hemorrhagic brain damage leading to schizencephaly-associated $C O L 4 A 1$ mutation. J Med Ultrason 42: 445-446, 2015.

21. Li QS, Meng FY, Zhao YH, Jin CL, Tian J and Yi XJ: Inhibition of microRNA-214-5p promotes cell survival and extracellular matrix formation by targeting collagen type IV alpha 1 in osteoblastic MC3T3-E1 cells. Bone Joint Res 6: 464-471, 2017

22. Tomotaki S, Mizumoto H, Hamabata T, Kumakura A, Shiota M, Arai H, Haginoya K and Hata D: Severe hemolytic jaundice in a neonate with a novel COL4A1 mutation. Pediatr Neonatol 57: 522-525, 2016.

23. Plaisier E and Ronco P: COL4A1-Related Disorders. In: GeneReviews $^{\circledR}$. Adam MP, Ardinger HH, Pagon RA, Wallace SE, Bean LJH, Stephens K and Amemiya A (eds). University of Washington, Seattle University of Washington, Seattle. GeneReviews is a registered trademark of the University of Washington, Seattle. All rights reserved, Seattle (WA), 1993.
24. Wen Y, Guo X, Hao J, Xiao X, Wang W, Wu C, Wang S, Yang T, Shen $\mathrm{H}$, Chen $\mathrm{X}$, et al: Integrative analysis of genome-wide association studies and gene expression profiles identified candidate genes for osteoporosis in Kashin-Beck disease patients. Osteoporos Int 27: 1041-1046, 2016.

25. Bi D, Wang H, Shang Q, Xu Y, Wang F, Chen M, Ma C, Sun Y, Zhao X, Gao C, et al: Association of COL4A1 gene polymorphisms with cerebral palsy in a Chinese Han population. Clin Genet 90: 149-155, 2016.

26. Hopwood B, Tsykin A, Findlay DM and Fazzalari NL: Microarray gene expression profiling of osteoarthritic bone suggests altered bone remodelling, WNT and transforming growth factor-beta/bone morphogenic protein signalling. Arthritis Res Ther 9: R100, 2007.

27. Livak KJ and Schmittgen TD: Analysis of relative gene expression data using real-time quantitative PCR and the $2^{-\Delta \Delta C \mathrm{~T}}$ method. Methods 25: 402-408, 2001.

28. Martin PJ, Haren N, Ghali O, Clabaut A, Chauveau C, Hardouin P and Broux O: Adipogenic RNAs are transferred in osteoblasts via bone marrow adipocytes-derived extracellular vesicles (EVs). BMC Cell Biol 16: 10, 2015.

29. Hooshmand S, Brisco JR and Arjmandi BH: The effect of dried plum on serum levels of receptor activator of NF- $\mathrm{BB}$ ligand, osteoprotegerin and sclerostin in osteopenic postmenopausal women: A randomised controlled trial. Br J Nutr 112: 55-60, 2014.

30. Catalano A, Morabito N, Basile G, Brancatelli S, Cucinotta D and Lasco A: Zoledronic acid acutely increases sclerostin serum levels in women with postmenopausal osteoporosis. J Clin Endocrinol Metab 98: 1911-1915, 2013.

31. Saad MN, Mabrouk MS, Eldeib AM and Shaker OG: Effect of MTHFR, TGF $\beta 1$, and TNFB polymorphisms on osteoporosis in rheumatoid arthritis patients. Gene 568: 124-128, 2015.

32. Komatsu Y, Ibi M, Chosa N, Kyakumoto S, Kamo M, Shibata T, Sugiyama Y and Ishisaki A: Zoledronic acid suppresses transforming growth factor- $\beta$-induced fibrogenesis by human gingival fibroblasts. Int J Mol Med 38: 139-147, 2016.

33. Iizuka M, Ogawa T, Enomoto M, Motoyama H, Yoshizato K, Ikeda $\mathrm{K}$ and Kawada N: Induction of microRNA-214-5p in human and rodent liver fibrosis. Fibrogenesis Tissue Repair 5: $12,2012$.

34. Li Y, Li A, Strait K, Zhang H, Nanes MS and Weitzmann MN: Endogenous TNFalpha lowers maximum peak bone mass and inhibits osteoblastic Smad activation through NF-kappaB. J Bone Miner Res 22: 646-655, 2007.

35. Gale DP, Oygar DD, Lin F, Oygar PD, Khan N, Connor TM, Lapsley M, Maxwell PH and Neild GH: A novel COL4A1 frameshift mutation in familial kidney disease: The importance of the C-terminal NC1 domain of type IV collagen. Nephrol Dial Transplant 31: 1908-1914, 2016.

36. Saeed H and Iqtedar M: Aberrant gene expression profiles, during in vitro osteoblast differentiation, of telomerase deficient mouse bone marrow stromal stem cells (mBMSCs). J Biomed Sci 22: 11, 2015

This work is licensed under a Creative Commons Attribution-NonCommercial-NoDerivatives 4.0 International (CC BY-NC-ND 4.0) License. 